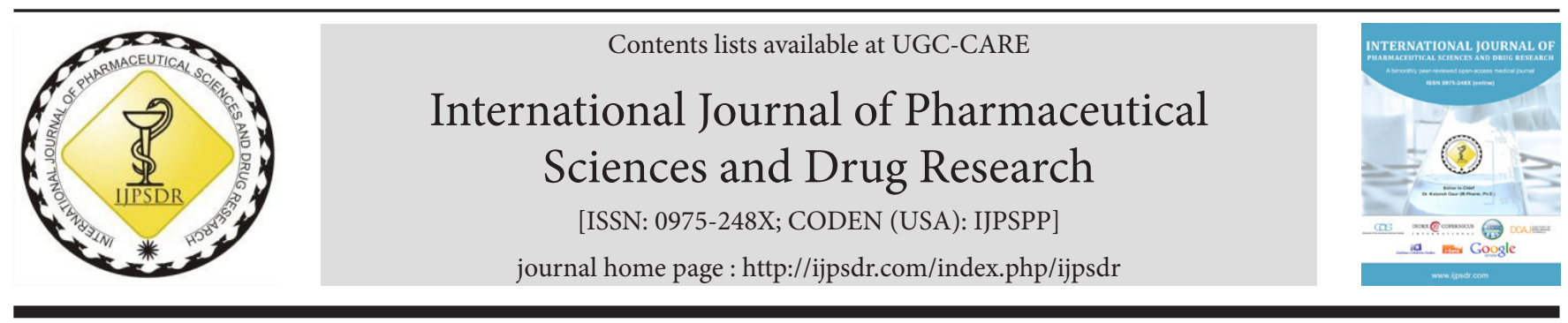

Review Article

\title{
High Rate Prevalence of Asymptomatic SARS-CoV-2 Infection: Comparative Epidemiology with other Pandemic Flu and Impact on COVID-19 Control Measures
}

\author{
Papiya Bigoniya* \\ DSKM College of Pharmacy, Faculty of Pharmacy, RKDF University, Gandhi Nagar, Bhopal-462024, India
}

\begin{tabular}{|c|c|}
\hline ART I C L I N F O & A B S T RACT \\
\hline $\begin{array}{l}\text { Article history: } \\
\text { Received: } 24 \text { May, } 2020 \\
\text { Revised: } 26 \text { June, } 2020 \\
\text { Accepted: } 03 \text { July, } 2020 \\
\text { Published: } 30 \text { July, } 2020 \\
\text { Keywords: } \\
\text { Asymptomatic carriers, } \\
\text { Coronavirus, } \\
\text { Severe acute respiratory } \\
\text { syndrome, } \\
\text { Silent spreaders. } \\
\text { DoI: } \\
\text { 10.25004/IJPSDR.2020.120415 }\end{array}$ & $\begin{array}{l}\text { Severe acute respiratory syndrome coronavirus } 2 \text { (SARS-CoV-2) is a novel coronavirus responsible for } \\
\text { the COVID-19 pandemic, an international public health emergency. Conventional routes of transmission } \\
\text { of SARS-CoV-2 are respiratory droplets and direct surface-based contact, similar to SARS-CoV, the Middle } \\
\text { East respiratory syndrome-related coronavirus (MERS-CoV), and highly pathogenic influenza. Some } \\
\text { clinical features of infectivity and viral susceptibility of SARS-CoV-2 are similar to SARS-CoV-1, MERS-CoV, } \\
\text { suggesting a difference in the viral tropism despite the phylogenetic homogeneity. The incubation period } \\
\text { of SARS-CoV-2 is in line with other coronaviruses, but with a lower case fatality rate, although the presence } \\
\text { of comorbidities can make it highly lethal. The major concern with SARS-CoV-2 is its ability to spread } \\
\text { silently by the asymptomatic and presymptomatic carriers. About } 70-80 \% \text { positive cases of COVID-19 are } \\
\text { coming out to be asymptomatic, presymptomatic, or very mild symptomatic, which is dangerously higher } \\
\text { compared to SARS-CoV-1, MERS-CoV, H1N1, and seasonal influenza. Asymptomatic and presymptomatic } \\
\text { carriers-based silent spreading of SARS-CoV-2 has become a major concern due to short serial interval, } \\
\text { and soaring level of virus shedding from the upper respiratory tract. Asymptomatic transmission is making } \\
\text { containment measures difficult to implement, now early detection and isolation of asymptomatic and } \\
\text { presymptomatic persons can be an effective strategy to control spread. High transmutability and silent } \\
\text { infection rate SARS-CoV-2 will hopefully help in the fast development of community herd immunity, } \\
\text { assuming to have } 12 \text { to } 14 \text { months active spread period compared to } 18 \text { to } 24 \text { months for previous pandemic } \\
\text { flu. Mass screening by rapid antibody tests, especially in congregate living conditions, mandatory use of } \\
\text { face masks, social-distancing, and strict execution of sanitization practices even after the relaxation of } \\
\text { lockdown, can effectively help to control the COVID-19 infection rate. }\end{array}$ \\
\hline
\end{tabular}

\section{COVID-19 OUTBREAK}

The current outbreak of coronavirus disease, first identified in Wuhan, China, has received official name COVID-19 from the World Health Organization (WHO). COVI comes from coronavirus, D stands for disease, and 19 represents 2019, as the virus was first identified in December 2019. The virus causing COVID-19 has been named "severe acute respiratory syndrome coronavirus 2" SARS-CoV-2 by the international committee on taxonomy of viruses (ICTV). The ICTV has recognized this virus as a sister to severe acute respiratory syndrome causing coronaviruses. This novel coronavirus is a new coronavirus that has not been previously identified. On 30th January 2020, the WHO declared that the SARS-CoV-2 outbreak constituted a public health emergency of international concern. Although coronaviruses endemic in humans normally show mild infection, such as, the common flu, the cross-species transmission has produced some unusually virulentstrains that can cause pneumonia and, in serious cases, acute respiratory distress syndrome and death.

\footnotetext{
*Corresponding Author: Dr. Papiya Bigoniya

Address: Principal, DSKM College of Pharmacy, RKDF University, Gandhi Nagar, Bhopal-462033, India

Email $\square$ : p_bigoniya2@hotmail.com

Relevant conflicts of interest/financial disclosures: The authors declare that the research was conducted in the absence of any commercial or financial relationships that could be construed as a potential conflict of interest.

Copyright (c) 2020 Papiya Bigoniya. This is an open access article distributed under the terms of the Creative Commons Attribution- NonCommercialShareAlike 4.0 International License which allows others to remix, tweak, and build upon the work non-commercially, as long as the author is credited and the new creations are licensed under the identical terms.
} 
As per the WHO, the coronavirus outbreak follows a fourphase outbreak pattern. Stage I: Imported and sporadic cases causing the first appearance of the disease. In this phase, the disease is first introduced to the population of a country, and positive cases begin to emerge by the people with travel histories to the infected areas. In this phase, a minimal number of persons got the infection, and disease is totally contained. Stage II: Local transmission starts to develop through positive individuals with travel history, or the persons come in direct contact with an infected person. This stage typically confers with transmission virus onto family members, friends, neighbors, and anyone coming in close vicinity of an infected person. In this stage, the viral transmission is monitored by contact tracing, isolating people with symptoms, strict screening measures, social distancing, and lockdown efforts. Stage III: In this stage, community transmission starts when it is difficult to trace the source of the infection spread. Individuals having no travel history to infected "hotspots," or contact with any positive person get infected. In this stage, it becomes impossible to contain the disease, and to stop the chain of transmission; large-scale lockdowns become the only option. Stage IV: Widespread outbreak is the final stage of transmission, making it a pandemic as the number of cases and deaths rapidly multiply. As per Indian Council of Medical Research (ICMR), currently, India is in stage II of coronavirus infection in spite of rapid spread without active contact or travel history. India has surpassed Russia as the third worst-hit country after the USA and Brazil. China has witnessed all stages of transmission and now is in stage IV, where the infection spreads in clusters. USA, Brazil, India, Russia, South Africa, Mexico, UK, Spain, Italy, and Iran are the most affected countries. ${ }^{[1]}$

\section{THE SARS-COV-2}

Genomic sequencing showed that this pathogenic coronavirus is $96.2 \%$ identical to bat coronavirus, and shares a $79.5 \%$ sequence identity to SARS-CoV. SARS-CoV-2 virus falls within the subgenus Sarbecovirus of the genus Betacoronavirus. The virus has zoonotic origins and has close genetic similarity to bat coronaviruses, suggesting it emerged from a bat-borne virus. SARS-CoV-2 is an enveloped, positive-sense, and single-stranded RNA virus. Each SARS-CoV-2 virion is approximately 50 to $200 \mathrm{~nm}$ in diameter, having four structural proteins, as $\mathrm{S}$ (spike), E (envelope), M (membrane), and N (nucleocapsid) proteins. The $\mathrm{N}$ protein holds the RNA genome, and the viral envelope is created by S, E, and M proteins together. ${ }^{[2]}$ The virus uses spike protein to attach and fuse with the membrane of a host cell.

SARS-CoV-2 enters human cells by binding to the receptor angiotensin-converting enzyme 2. For cellular entry, coronavirus uses the ACE2 receptor as a keyhole to unlock the cell. Interferons act as the primary defenses of the body against viruses, and function as "first responders" in case of foreign pathogen invasion. The immune system releases interferons to alert about the presence of pathogenic coronavirus in the body. The gene that encodes the ACE2 receptor gets stimulated by interferons ramping up expression of ACE2 receptors, which then acts as a carrier for SARS-CoV-2 to infect even more cells, thus, using body's immune response against it. No clinically effective vaccines or specific antiviral drug is currently available for the treatment of COVID-19 infections. ${ }^{[3]}$

\section{Infectivity and Viral Susceptibility}

Conventional routes of transmission of SARS-CoV-2 consist of respiratory droplets produced from coughs or sneezes and direct contact, mechanisms that probably occur with SARS-CoV, the MERS-CoV, and highly pathogenic influenza. ${ }^{[4]}$ Indirect contact via contaminated surfaces has become a serious matter of concern. The virus can remain viable on plastic and steel for up to three days, on cardboard for up to one day, and copper for approximately four hours. The virus is inactivated by soap, which destabilizes its lipid bilayer. SARS-CoV-2 can be detected in the gastrointestinal tract, saliva, and urine of an infected person. Viral RNA has also been found in stool samples from infected individuals. ${ }^{[5]}$ Some clinical characteristics of SARS-CoV-2 and SARS$\mathrm{CoV}$ are different despite the phylogenetic homogeneity. The clinical features of COVID-19 mimic fever and cough as the dominant symptoms similar to SARS-CoV. In contrast, gastrointestinal symptoms were uncommon, suggesting a difference in the viral tropism of SARS-CoV-2 compared to SARS-CoV, MERS-CoV, and seasonal influenza. ${ }^{[6]}$

The median age of the COVID-19 patients was 47 years, with $41.9 \%$ of the female patients. Young children and females were less likely to get infected with SARS-CoV-2 than adolescents and males. The lower incidence of positive results in these two groups may have resulted from less exposure to the virus or biologic resistance. ${ }^{[7]}$ In other studies, investigators have found that infected children and females were less likely to have a severe disease than adults and males, respectively. ${ }^{[6,8]}$ The most common symptoms of COVID-19 are fever, cough, and lymphocytopenia, and less commonly, diarrhea, nausea, or vomiting. Chest computed tomography showed ground-glass opacity as the most common radiologic finding. ${ }^{[6]}$ Initially, it was estimated that the median incubation period SARS-CoV-2 is 2 to 7 days. Analysis based on 158 confirmed cases in China estimated a median incubation period of 5 days with a range of 2 to 14 days, ${ }^{[9]}$ with onset symptoms in 3 to 6 days after assumed exposure. ${ }^{[10]}$ The incubation period of SARS-CoV-2 is 2 to 14 days, which is in line with other human coronaviruses, SARS, and MERS. ${ }^{[11,12]}$ The incubation period of non-SARS human coronavirus is 2 to 5 days. ${ }^{[13]}$ The knowledge of the incubation period is vital for public health activities, 
including active monitoring, surveillance, control, and modeling of the disease control system.

Despite the number of deaths associated with COVID-19, it appears to have a lower case fatality rate than either SARS-CoV or MERS-CoV. Approximately 35\% of reported patients with MERS-CoV infection have died, ${ }^{[14]}$ whereas, SARS-CoV has a fatality rate of $11 \%$, which can be more than $50 \%$ with patients above 65 years. ${ }^{[15]}$ The case fatality rate among people infected with highly pathogenic avian influenza has ranged from 36 to $60 \%$, which is alarmingly high. ${ }^{[16]}$ The death rate with SARS-CoV-2 can vary from $1.4 \%$ as reported in China ${ }^{[6]}$ to $3.2 \%$ reported by $\mathrm{WHO},{ }^{[17]}$ although much higher lethality of 13 to $15 \%$ was reported by other studies conducted in China. ${ }^{[10,18]}$ The overall fatality rate of persons with confirmed COVID-19 in the Italian population, based on data up to 17th March, was $7.2 \%$. Whereas between ages 60 to 69 , 70 to 79 , and above 80 , the death rate was $8.6,35.6$, and $52.3 \%$, respectively. The presence of comorbidities, like heart disease, diabetes, and cancer, can increase the risk of mortality by $25 \%{ }^{[8]}$ The fatality rate is defined as the number of deaths in persons tested positive, divided by the number of SARS-CoV-2 cases. India's fatality rate per million population currently is lowest in the world, which is below $2 \%$. The testing strategy has a significant influence on the fatality rate, as countries like the Republic of Korea, Singapore, and Germany have adopted a wide testing strategy for SARS-CoV-2. This has led to the identification of a large number of individuals with mild or limited symptoms, with a much lower case-fatality rate compared to Italy or the USA.

\section{Transmission}

People get infected with coronavirus without showing symptoms. This period can be of several days before symptoms kick in. The infected person does not have a cough, fever, and other signs of illness but can transmit the virus to others. Evidence shows that SARS-CoV-2 has this ability to spread silently. Analysis of COVID-19 cases indicates that most of the infected people are generally fine, living a healthy daily life. In many instances, the infected persons do not even know that they have already been infected and can transmit the virus to family members, neighbors, friends, and strangers. This category of infected people is designated as "silent spreaders." Silent spreaders remarkably contribute to the transmission of the COVID-19 disease, basically called the third phase of spread or community transmission.

The first cases of novel coronavirus (2019-nCoV) infected pneumonia (NCIP) occurred in Wuhan, Hubei Province, China, in December 2019 and January 2020. Reports soon started to come out about the transmission of the virus in other geographical regions by infected travelers. Person-to-person transmission of this novel coronavirus in hospital and family settings among close contacts is very high. An extremely soaring rate of COVID-19 outbreak correlates transmission from the asymptomatic patient and the three-phase outbreak patterns. ${ }^{[18,19]}$ COVID-19 infection in Germany appears to have been transmitted from a mildly symptomatic convalescent patient 1 (German citizen) via an asymptomatic contact with the index patient (Chinese citizen) during the incubation period, in whom the illness was brief and nonspecific. A high sputum viral load observed in the patient 1 , lately confirmed prolonged shedding of the virus after recovery. The fact emphasizes that asymptomatic persons are potential sources of COVID-19 infection transmission dynamics of the current outbreak. ${ }^{[20]}$ Recent evidence of SARS-CoV-2 transmission by mildly symptomatic and asymptomatic persons signals that time from exposure to onset of infectiousness (latent period) can be shorter than the incubation period with important implications for transmission dynamics. Based on the 14 days incubation period currently, the length of quarantine or active monitoring of persons potentially exposed to SARS-CoV-2 is done. In some rare cases, longer monitoring periods might be justified as among infected persons, $1.01 \%$ can develop symptoms after the end of a 14 day quarantine period. ${ }^{[21]}$

\section{Silent Spreaders of Coronavirus}

A "silent transmission" occurs when someone who has contracted the virus shows no symptoms but passes the virus to someone else. Silent spreaders are divided into three categories, asymptomatic, presymptomatic, and very mildly symptomatic. Asymptomatic people carry the active virus but never develop any symptoms. Epidemiologists verify that asymptomatic people do not have common symptoms like fever, gastrointestinal problems, cough, or breathing difficulty. It is very tough for medical professionals to identify someone as infected, while showing no symptoms. Asymptomatic carriers can only be confirmed by finding and testing people who were in close contact with any COVID-19 patients. As per the WHO, about $25 \%$ of positive tested asymptomatic people, continued to show no signs in follow-up checkups. ${ }^{[22]}$ Since asymptomatic infected person does not know about their infection status, they may not take precautions advised while interacting with people. Presymptomatic people are infected and incubating the virus, but not showing any symptoms yet. Following coronavirus infection, it takes five to six days, sometimes, even two weeks to develop symptoms according to the research conducted between January and February 2020, published in Annals of Internal Medicine. ${ }^{[21]}$ The time lag between getting infected with the virus and showing symptoms is called the presymptomatic phase.

Very mildly symptomatic people feel slightly unwell from a COVID-19 infection, but continue to come in close contact with others. Though spreading COVID-19 by symptomatic people having very mild cough or fever cannot be counted as silent transmission, though this happens when people confuse the condition with common 
seasonal flu. Very mildly symptomatic people, when they continue to go to public places, may unknowingly spread the disease in the early days of incubation period when they are most infectious. A completely asymptomatic person who never develops any symptoms can transmit the infection. Though silent spreaders have no or mild symptoms, they still infect others who can become very sick with COVID-19. It is truly impossible to determine the impact of asymptomatic cases on spread except massscale testing. The data of a small group clinical study on 24 positive tested people in Nanjing, China, shows that those who do not have overt symptoms at the time of testing continued to be asymptomatic one to three weeks after diagnosis had a median age of 14 .

Presymptomatic cases of COVID-19 is more common category than asymptomatic. About $75 \%$ of people who test positive without showing symptoms turn out to be presymptomatic, displaying coughing, fatigue, fever, and other signs in the later follow-up checks. ${ }^{[22]}$ As per WHO, a presymptomatic person can transmit this virus, most likely in the one to three days period before they start showing symptoms. However, presymptomatic people appear to be most infectious around the time when it starts showing symptoms. ${ }^{[22]}$ In mid-March, 82 residents of a nursing home in King County, Washington, tested positive for the coronavirus. Half of them were free from any symptom when tested for the virus, and most went on to develop symptoms. The coronavirus spread rapidly through the facility within two weeks despite applying isolation policy suggesting transmission from asymptomatic and presymptomatic residents, who were not recognized as having SARS-CoV-2 infection and, therefore, were not isolated. ${ }^{[23]}$ Another study in Singapore, done between February and March, had reported similar evidence of presymptomatic spread among people going to public places. ${ }^{[24]}$

\section{Silent Transmission Fueling Pandemic}

Silent transmission of infectious disease occurs via the asymptomatic carrier who is infected with the pathogen without any symptoms. Asymptomatic carriers play a critical role in the transfer of common infectious diseases, such as, typhoid, influenzas, tuberculosis, measles, cholera, dengue, human immunodeficiency virus (HIV), and now the COVID-19. Asymptomatic carriers are associated with not only the viral disease but also with diseases caused by bacteria and mycobacterium. Controlling asymptomatic disease has become crucial in concern to public health for mitigating the spread of common infectious diseases. The history of the asymptomatic carrier for the first time was connected with Mary Mallon, interestingly nicknamed as Typhoid Mary. She was an asymptomatic carrier of Salmonella typhi, causing typhoid fever in New York City during the late $1800 \mathrm{~s}$. She was a cook for several families and soldiers, and nearly 50 cases of typhoid fever were traced back to her. She was quarantined on an island surrounding Manhattan until her death.
WHO estimates that approximately 390 million people get infected with dengue virus worldwide each year, out of which only 96 million develop clinical manifestations, with approximately $75 \%$ of asymptomatic patients. Chen et al. reported the presence of dengue virus in people of southern Taiwan, despite the fact that no epidemic has been reported in the past 10 years, demonstrating silent transmission. ${ }^{[25]}$ The prevalence of asymptomatic carriage of influenza infections ranges from 60 to $75 \%$, which has a very short generation time and spread very quickly. ${ }^{[26]}$ Asymptomatic measles infections are common among measles-immune persons, but transmission from asymptomatic cases is very rare. As per the European Centre for Disease Prevention and Control (European Union), an estimated 1.7 billion people had latent tuberculosis having a "dormant" form of tuberculosis. Latent tuberculosis infection carriers are asymptomatic and not infectious but can spread disease at a later stage resulting in active tuberculosis. ${ }^{[27]}$ Asymptomatic carriers can transfer cholera usually for a short period, though a few individuals may excrete the Vibrio cholerae for a prolonged period. Asymptomatic HIV infection is the second stage of acquired immunodeficiency syndrome (AIDS), when there are no symptoms, also called clinical latency. During this stage, the virus multiplies in the body, and the immune system slowly weakens. The patients are called longterm nonprogressors, and the duration can be 10 years or more, depending on the HIV multiplication rate and how the immune system responds to the virus. Asymptomatic carriers have a significant role in fueling the epidemic and pandemic of typhoid, influenzas, dengue, HIV, and COVID-19.

\section{Role of Silent Spreaders in COVID Pandemic}

The evidence of presymptomatic transmission in Singapore and China, between January to March, supports the likelihood that viral shedding occurs in the absence of symptoms and before symptom onset. ${ }^{[28,29]}$ Asymptomatic and presymptomatic SARS-CoV-2 infections in residents of a nursing facility in King County, Washington, suggests that symptom screening initially fails to identify approximately one-half of residents with SARS-CoV-2 infection. Unrecognized asymptomatic and presymptomatic infections contribute to large scale transmission in such settings. ${ }^{[30]}$ Even though it was a nightmare for the 3,700 passengers and crew members trapped off the coast of Japan in Diamond Princess cruise ship, it gave researchers a unique chance to study COVID-19. This cruise ship docked at Yokohama Bay, Japan, temporarily became the largest cluster of COVID-19 cases outside China in 1st week of February. Passengers were held under quarantine over two weeks, and researchers found that $46.5 \%$ of infected people did not have symptoms at the time of testing. Many eventually did develop symptoms; still, $18 \%$ of infected cases remained asymptomatic. ${ }^{[31]}$ 
Silent carriers of coronavirus may play a significant role in spreading the disease, according to research conducted in Iceland. Researchers from deCODE genetics and Iceland's Directorate of Health and National University Hospital, Iceland, examined more than 20,000 people, which is about $6 \%$ of the country's population in the $3 \mathrm{rd}$ and 4 th week of March. Targeted testing of more than 9,000 people with COVID-19 symptoms identified $13 \%$ positive cases. Out of more than 10,000 people, who voluntarily joined screening on an open invitation without exhibiting symptoms, about $0.8 \%$ was tested positive for coronavirus. More than 2,000 people were randomly selected for screening, out of which $0.6 \%$ were tested positive, indicating that a significant number of people could have the virus without exhibiting symptoms. About $60 \%$ of the participants who tested positive reported having had contact with a known infected person. Notably, $43 \%$ of the participants have tested positive but did not have any symptoms, although symptoms developed later in some of them. ${ }^{[7]}$ Evidence shows that transmission from asymptomatic infector to close contacts can lead to severe COVID-19 pneumonia. Clinical characteristics of 24 cases with asymptomatic infection from close contacts were screened that showed the transmission potential of asymptomatic COVID-19 virus carriers. The communicable period could be up to three weeks, and some of the communicated patients develop severe illness. ${ }^{[32]}$

Air, surface, environmental, and personal protective equipment got contaminated from infected patients. ${ }^{[33]}$ Environmental contamination with SARS-CoV-2 has been reported, and the possibility of indirect transmission through fomites is a big concern now, as after lockdown also people are getting infected while at home. Vegetables, grocery items, and packed food objects can be contaminated directly by droplets or through contact with an infected person's contaminated hands due to nonrigorous hygiene practices. Researchers have sequenced more than 600 samples of the virus and found more than 291 mutations. ${ }^{[7]}$ The extent of infectivity and lethality of coronavirus changes with its mutation. Human natural defense mechanisms can react differently towards different mutated strains of COVID-19.

\section{Transmissibility Difference of COVID with other Pandemic Flu}

Dr. Anthony Fauci, director of the US National Institute of Allergy and Infectious Diseases, said in a press conference on 28th January, that "in all the history of respiratory-borne viruses of any type, the asymptomatic transmission has never been the driver of outbreaks." On 1st February 2020, the WHO also indicated that "transmission from asymptomatic cases is likely not a major driver of transmission.."[34] All these assumptions went incorrect soon enough, when reports started to come of rapid escalation of COVID positive cases form Italy and Iran, followed by Germany and the USA. The latest worldwide data suggests that silent transmission of the COVID-19 virus is playing a dangerous role in electrifying the spread of the pandemic locally, as well as, across the globe. The data reveals that currently, around 60 to $70 \%$ of the tested people in India have been found antibody positive despite showing no symptoms. Such individuals look healthy, and as silent carriers would have played a vital role in the spread of the virus, if not contained by the strict lockdown. Collectively all the current research conducted on COVID cases between January to April in Singapore, China, Iceland, Germany, and the USA shows the extent of SARS-CoV-2 spread by the asymptomatic carriers. COVID has started with such ferocity that mostly all the countries effected had to implement partial or strict lockdown policy. Countries like India, applying lockdown sooner before induction of phase II, were able to control the phase III spike effectively, whereas, the countries implementing in later stages are paying a high price. However, asymptomatic carriers of the dreaded virus have been ignored by most of the western countries.

The influenza pandemic of 1918-1919 killed nearly 50 million (5 crores) of people more than World War I, making it one of the deadliest pandemics in human history. The Spanish influenza virus had a profound virulence, with a mortality rate of $2.5 \%$, with the death rate of 20 times higher for 15 to 35 -year-olds. People were struck with flu and died rapid deaths, some times within hours. Though no documented research was found on asymptomatic carriers of the Spanish flu, this level of contagious spread would have been possible only with silent carriers. This possibility can be correlated with the fact that officials of San Francisco, one of the hard-hit cities of the US, ordered everyone to wear face masks and banned public gatherings. The restrictions worked, and the numbers of cases and fatalities decreased within weeks. Ensured that the disease spread had slowed down, ban on public gatherings was abolished along with the mandatory wearing of masks, and just after four weeks, the flu rebounded with a prolonged second wave reporting more cases and deaths than the first one.

The asymptomatic infection rate was reported to be less than $0.1 \%$ for MERS cases. ${ }^{[35]}$ Despite a more than $40 \%$ mortality rate, due to the slower spread of MERS, fewer than 200 cases worldwide were reported during the 18 months' period, since the outbreak in 2012. All cases were virtually directly or indirectly related to transmission in the Arabian peninsula, minimizing the advent of super spreaders or a mutation in the MERS virus. Arbitrary estimates of asymptomatic infection were in the range of 30 to $50 \%$ for the H1N1 epidemic, ${ }^{[26]}$ which estimated to have caused about 284,000 deaths in 20 months duration. The incidence of asymptomatic cases was found to be 7.5 to $13 \%$ out of all SARS-CoV-1 positive cases. ${ }^{[36]}$ SARS-CoV-1 outbreak in the 2003-2004 had infected approximately 8,100 persons in limited geographic areas and killed close to $10 \%$ of those infected 
in 8 months. Whereas, within 8 months, SARS-CoV-2 has infected more than 25 million people and continues to spread rapidly around the world while more than one third (approximately 2.5 billion) of the world's population was under lockdown for 2 to 3 months.

High level of SARS-CoV-2 shedding from the upper respiratory tract of presymptomatic patients was observed. ${ }^{[37]}$ Influenza asymptomatic persons, generally, have lower quantitative viral loads in upper respiratory tract secretions, and a shorter duration of viral shedding. ${ }^{[38]}$ Live coronavirus clearly sheds at high concentrations from the nasal cavity even before symptom development. Because of this, traditional symptom-based screening or only contact tracing-based testing does not have much utility in the COVID containment measure. Ultimately, the rapid spread of COVID-19 across the globe is clear evidence of SARS-CoV-2 transmission from asymptomatic persons. ${ }^{[39]}$ The eventual need to relax current lockdown measures urges for broadened SARS-CoV-2 testing to include asymptomatic persons in prioritized settings of congregate living situations, like in slams, nursing facilities, prisons, jails, mental health facilities, homeless shelters, and hospitalized inpatients. The general public should now be encouraged to use face masks always after the relaxation of lockdown, also when in crowded outdoor or indoor spaces, along with the following common sanitization practices. ${ }^{[40]}$ This unprecedented pandemic calls for unprecedented measures to the level of government, as well as, the general public to defeat it ultimately.

\section{CONCLUSION}

Scientists are suggesting authorities, managing COVID-19 lockdowns, to learn from history and avoid slowing containment efforts too soon. Self-isolation, quarantining, and other social-distancing measures have helped to control the COVID-19 infection rate. All the scientific findings on COVID-19 suggest that to control the pandemic, it is not enough to limit contact with persons having symptoms, as persons without symptoms might also transmit infection. The current rate of asymptomatic and presymptomatic COVID-19 positive persons has increased the challenges of containment measures to control the transmission. Asymptomatic transmission definitely makes containment measures difficult to implement. The strategy must now focus on predicated early detection and isolation of asymptomatic persons along with extensive control measures, like isolation, quarantine, school closures, travel, and mass gatherings restrictions. Early detection of asymptomatic and presymptomatic persons are only possible with quick result oriented mass population testing measures based on reverse transcription polymerase chain reaction (RT-PCR) or more specifically, detection of IgM/IgG antibodies against SARS-CoV-2 by rapid lateral flow immunoassay. The magnitude of this impact will be purely dependent upon the extent and duration of transmissibility, while a patient is asymptomatic or presymptomatic, which, to date, has been extended from 14 to 28 days by authorities of many countries, as many asymptomatic and mild presymptomatic persons are now tested to be SARS-CoV-2 positive up to 28 days.

The researchers have found that the time interval between infection and subsequent transmission, called serial interval for SARS-CoV-2, is approximately 4 to 8 days. The serial interval for SARS-CoV-1 was 7 days. A shorter serial interval makes an epidemic spread rapidly and harder to contain. Naturally, pandemics eventually ends, when the pathogen runs out of individuals to infect in its course of progression. This period helps the population to develop "herd immunity," as, during this disease susceptible period, enough of the population became immune. All the previous respiratory borne pandemics like Spanish flu, MERS, H1N1, and SARS-CoV-1 were active on an average of 18 to 24 months. Depending on the viral strain, lethality susceptible individuals die between these active disease spread periods. SARS-CoV-2 is spreading at a much faster rate than MERS, H1N1, and SARS-CoV-1, as it is showing a very high rate of asymptomatic positive cases, in addition to the shorter serial interval. Despite many similarities between SARS-CoV-1 and SARS-CoV-2, including genetic relatedness, transmission characters, and incubation period, trajectories of the two epidemics have veered in dramatically speculated to be due to drastically high rate of asymptomatic carriers of SARS-CoV-2. The current pandemic of SARS-CoV-2 has a much higher silent infection rate, and thus, presumably, herd immunity will also arrive swiftly and assumed to have 12 to 14 months active spread period. Rapid antibody tests can be used to determine the percentage of the population that has contracted the disease, and that is, therefore, presumed to be immune.

\section{REFERENCES}

1. World Health Organization. Current WHO phase of pandemic alert for pandemic (H1N1) 2009. Available from: https://www.who.int/ csr/disease/swineflu/phase/en/ [Lastaccessed on 2020 24th April]

2. Lu R, Zhao X, Li J, Niu P, Yang B, Wu H, et al. Genomic characterisation and epidemiology of 2019 novel coronavirus: Implications for virus origins and receptor binding. Lancet 2020;395:565-574.

3. Wu C, Liu Y, Yang Y, Zhang P, Zhong W, Wang Y, et al. Analysis of therapeutic targets for SARS-CoV-2 and discovery of potential drugs by computational methods. Acta Pharmaceutica Sinica B. 2020. Available from: https://doi.org/10.1016/j.apsb.2020.02.008 [Last accessed on 2020 22nd April]

4. Lei H, Li Y, Xiao S, Lin CH, Norris SL, Wei D, et al. Routes of transmission of influenza A H1N1, SARS CoV, and norovirus in air cabin: comparative analyses. Indoor Air. 2018;28:394-403.

5. van Doremalen N, Bushmaker T, Morris DH, Holbrook mg, Gamble A, Williamson BN, et al. Correspondence: Aerosol and surface stability of SARS-CoV-2 as compared with SARS-CoV-1. N Engl J Med. 2020;382(16):1564-1567.

6. Guan W, Ni Z, Hu Y, Liang W, Ou C, He J, et al. Clinical characteristics of coronavirus disease 2019 in China. N Engl J Med. 2020;382: $1708-1720$. 
7. Gudbjartsson DF, Helgason A, Jonsson H, Magnusson OT, Melsted P, Norddahl GL, et al. Spread of SARS-CoV-2 in the Icelandic population. N Engl J Med. 2020. Available from: https://doi.org/10.1056/ NEJMoa2006100.

8. Onder G, Rezza G, Brusafer ro S. Case-fatality rate and characteristics of patients dying in relation to COVID-19 in Italy. J Am Med Assoc. 2020. Available from: https://doi.org/10.1001/jama.2020.4683.

9. Linton $\mathrm{nm}$, Kobayashi T, Yang Y, Hayashi K, Akhmetzhanov AR, Jung SM, et al. Incubation period and other epidemiological characteristics of 2019 novel coronavirus infections with right truncation: A statistical analysis of publicly available case data. J Clin Med. 2020;9(2). Available from: https://doi.org/10.3390/ jcm9020538.

10. Huang C, Wang Y, Li X, Ren L, Zhao J, Hu Y, et al. Clinical features of patients infected with 2019 novel coronavirus in Wuhan, China. Lancet. 2020;395:497-506.

11. Varia M, Wilson S, Sarwal S, McGeer A, Gournis E, Galanis E, et al. Investigation of a nosocomial outbreak of severe acute respiratory syndrome (SARS) in Toronto, Canada. Can Med Assoc J. 2003;169(4):285-292.

12. Virlogeux V, Fang VJ, Park M, Wu JT, Cowling BJ. Comparison of incubation period distribution of human infections with MERS-CoV in South Korea and Saudi Arabia. Sci Rep. 2016;6. Available from: https://doi.org/10.1038/srep35839.

13. Lessler J, Reich NG, Brookmeyer R, Perl TM, Nelson KE, CummingsDAT. Incubation periods of acute respiratory viral infections: A systematic review. Lancet Infect Dis. 2009;9(5):291-300.

14. World Health Organization. Middle East respiratory syndrome coronavirus (MERS-CoV). 2019. Available from: https://www.who.int/ news-room/fact-sheets/detail/middle-east-respiratory-syndromecoronavirus-(mers-cov) [Last accessed on 28th April 2020]

15. Chan-Yeung $\mathrm{M}, \mathrm{Xu}, \mathrm{RH}$. SARS: Epidemiology. Respirology (Carlton, Vic.). 2003;8 Suppl:S9-14.

16. Wu ZQ, Zhang Y, Zhao N, Yu Z, Pan H, Chan TC, et al. Comparative epidemiology of human fatal infections with novel, high (H5N6 and H5N1) and low (H7N9 and H9N2) pathogenicity avian influenza A viruses. Int J Environ Res Public Health. 2017;14(3):263. Available from: https://doi.org/10.3390/ijerph14030263

17. World Health Organization. Coronavirus disease (COVID-2019) situation reports. 2019. Available from: https://www.who.int/ emergencies/diseases/novel-coronavirus-2019/situation-reports/ [Last accessed on 2020 22nd April]

18. Chen N, Zhou M, DongX, Jieming Q, Gong F, Han Y, etal. Epidemiological and clinical characteristics of 99 cases of 2019 novel coronavirus pneumonia in Wuhan, China: a descriptive study. Lancet. 2020;395:507-513.

19. Chan JF, Yuan S, Kok KH, Kai-Wang K, Chu H, Yang J, et al. A familial cluster of pneumonia associated with the 2019 novel coronavirus indicating person-to-person transmission: a study of a family cluster. Lancet. 2020;395:514-523.

20. Rothe C, Schunk M, Sothmann P, Bretzel G, Froeschl G, Wallrauch C, et al. Transmission of 2019-nCoV infection from an asymptomatic contact in Germany. N Engl J Med. 2020;382:970-971.

21. Lauer SA, Grantz KH, Bi Q, Jones FK, Zheng Q, Meredith hr, et al. The incubation period of coronavirus disease 2019 (COVID-19) from publicly reported confirmed cases: Estimation and application. Ann Intern Med 2020. Available from: https://doi.org/10.7326/M20-050

22. World Health Organization. COVID-19-virtual press conference-01 April 2020. Available from: https://www.who.int/docs/defaultsource/coronaviruse/transcripts/who-audio-emergenciescoronavirus-press-conference-full-01apr 2020 -final. pdf?sfvrsn=573dc140_2

23. Centers for Disease Control and prevention. Asymptomatic and presymptomatic SARS-CoV-2 infections in residents of a long-term care skilled nursing facility-King County, Washington, March 2020. Morbidity and Mortality Weekly Report. 2020;69(13):377-381.

24. Centers for Disease Control and prevention. Presymptomatic transmission of SARS-CoV-2-Singapore, 23rd January-16th March. Morbidity and Mortality Weekly Report. 2020;69(14):411-415.

25. Chen WJ, Chen SL, Chien LJ, Chen CC, King CC, Harn MR, et al. Silent transmission of the dengue virus in southern Taiwan. Am J Trop Med Hyg. 1996;55(1):12-16.

26. Furuya-Kanamori L, Cox M, Milinovich GJ, Magalhaes RJ, Mackay IM, Yakob L. Heterogeneous and dynamic prevalence of asymptomatic influenza virus infections. Emerg Infect Dis. 2016;22(6):1052-1056.

27. European Centre for Disease Prevention and Control. An agency of the European Union. The sleeping giant: the danger of neglecting latent tuberculosis infection. 2018. Available from: https://www. ecdc.europa.eu/en/news-events/sleeping-giant-danger-neglectinglatent-tuberculosis-infection

28. Wang Y, Liu Y, Liu L, Wang X, Luo N, Ling L. Clinical outcome of 55 asymptomatic cases at the time of hospital admission infected with SARS-coronavirus-2 in Shenzhen, China. J Infect Dis. 2020;jiaa119. Available from: https://doi.org/10.1093/infdis/jiaa119

29. Wei WE, Li Z, Chiew CJ, Yong SE, Toh MP, Lee VJ. Presymptomatic transmission of SARS-CoV-2-Singapore, 23rd January-16th March, 2020. mmWR Morb Mortal Wkly Rep. 2020;69:411-415.

30. Kimball A, Hatfield KM, Arons M, James A, Taylor J, Spicer K, et al. Asymptomatic and presymptomatic SARS-CoV-2 infections in residents of a long-term care skilled nursing facility-King County, Washington, March 2020. mmWR Morb Mortal Wkly Rep. 2020;69:377-381.

31. Inui S, Fujikawa A, Jitsu M, Kunishima N, Watanabe S, Suzuki Y, et al. Chest CT findings in cases from the cruise ship "Diamond Princess" with coronavirus disease 2019 (COVID-19). Radiolog Cardiothoracic Imag. 2020;2(2). Available from: https://doi.org/ $10.1148 /$ ryct.2020200110

32. Hu Z, Song C, Xu C, Jin G, Chen Y, Xu X, et al. Clinical characteristics of 24 asymptomatic infections with COVID-19 screened among close contacts in Nanjing, China. Sci China Life Sci. 2020;63. Available from: https://doi.org/10.1007/s11427-020-1661-4

33. Ong SWX, Tan YK, Chia PY, Lee TH, Ng OT, Wong MSY, et al. Air, surface environmental, and personal protective equipment contamination by severe acute respiratory syndrome coronavirus 2 (SARS-CoV-2) from a symptomatic patient. J Am Med Assoc. 2020;323(16):1610-1612.

34. World Health Organization. Novel coronavirus (2019-nCoV): situation report, 12 (Report). 1st February 2020. Available from: https://www.who.int/docs/default-source/coronaviruse/situationreports/20200201-sitrep-12-ncov.pdf?sfvrsn=273c5d35_2

35. Song YJ, Yang JS, Yoon HJ, Nam HS, Lee SY, Cheong HK, et al. Asymptomatic Middle East respiratory syndrome coronavirus infection using a serologic survey in Korea. Epidemiol Health. 2018;40:e2018014. Available from: https://doi.org/10.4178/epih. e2018014

36. Wilder-Smith A, Teleman MD, Heng BH, Earnest A, Ling AE, Leo YS. Asymptomatic SARS coronavirus infection among healthcare workers, Singapore. Emerg Infect Dis. 2005;11(7):1142-1145.

37. Wölfel R, Corman VM, Guggemos W, Seilmaier M, Zange S, Müller MA, et al. Virological assessment of hospitalized patients with COVID-2019. Nature 2020. Available from: https://doi.org/10.1038/ s41586-020-2196-x

38. Ip DKM, Lau LLH, Leung NHL, Fang VJ, Chan KH, Chu DKW, et al. Viral shedding and transmission potential of asymptomatic and paucisymptomatic influenza virus infections in the community. Clin Infect Dis. 2017;64:736-742.

39. Arons mm, Hatfield KM, Reddy SC, Kimball A, James A, Jacobs JR, et al. Presymptomatic SARS-CoV-2 infections and transmission in a skilled nursing facility. $\mathrm{N}$ Engl J Med. 2020. Available from: https://doi.org/10.1056/NEJMoa2008457

40. Centers for Disease Control and Prevention. Use of cloth face coverings to help slow the spread of COVID-19. 2020. Available from: https://www.cdc.gov/coronavirus/2019-ncov/prevent-gettingsick/cloth-face-cover.html

HOW TO CITE THIS ARTICLE: Bigoniya P. High rate prevalence of asymptomatic SARS-CoV-2 infection: comparative epidemiology with other pandemic flu and impact on COVID-19 control measures. Int. J. Pharm. Sci. Drug Res. 2020;12(4):415-421. DOI: 10.25004/IJPSDR.2020.120415 